\title{
KAJIAN TAMPILAN FISIK, CITRA MEREK DAN PEMASAR DARI MULUT KE MULUT TERHADAP KEPUTUSAN PEMBELIAN PADA SALON NOONA BEAUTY KOREA KOTA BARABAI KABUPATEN HULU SUNGAI TENGAH
}

\author{
Cici Asmawati ${ }^{1}$ \\ e-mail : cici.asmawati@stiabinabanuabjm.ac.id \\ Riky Welli Saputra ${ }^{2}$ \\ e-mail : rikywelli@stiabinabanuabjm.ac.id \\ STIA Bina Banua Banjarmasin
}

\begin{abstract}
The purpose of this study was to analyze the physical appearance, brand image and marketer's word of mouth either partially or simultaneously influence the purchasing decision at Noona Beauty Korea salon in Barabai, Hulu Sungai Tengah Regency.

The population in this study were all customers or consumers of the Noona Beuty Korea salon in Barabai, Hulu Sungai Tengah Regency. The number of samples is 100 respondents. The sampling technique in this study used a random sampling technique, or random sampling. The data in this research were obtained directly from interviews by distributing questionnaires. The analytical tool used is the research instrument test, classical assumption test, multiple linear regression, $t$ test, $\mathrm{F}$ test and $\mathrm{R} 2$ test

The results showed that there was an effect of Physical Appearance on Purchase Decisions at Noona Beauty Salon Korea Barabai, Hulu Sungai Tengah Regency. There is an influence of Brand Image on Purchase Decision at Salon Noona Beauty Korea Barabai, Hulu Sungai Tengah Regency. There is the influence of marketers by word of mouth on purchasing decisions at Noona Beauty Salon Korea Barabai, Hulu Sungai Tengah Regency. There is a joint influence between the variables of Physical Appearance, Brand Image, and Word of mouth Marketers on Purchase Decisions at Noona Beauty Salon Korea Barabai, Hulu Sungai Tengah Regency.
\end{abstract}

Keywords: Physical Appearance, Brand Image, Word of mouth Marketers, Purchase Decision 


\section{PENDAHULUAN}

Perilaku pembelian konsumen dipengaruhi oleh faktor eksternal dan faktor internal (Hawkins et al., 2013). Faktor yang meliputi unsur kebudayaan, kelas sosial maupun kondisi demografi dan geografi yang mencakup seluruh keberadaan yang ada dikehidupan sekitarnya, sedangkan faktor internal terdiri atas kepribadian, psikis, emosi, tingkah laku serta aktivitas penjualan. Persaingan usaha yang semakin ketat, khususnya pada salon maupun klinik kecantikan tentunya para pengusaha berlomba-lomba mencari konsumen dengan berbagai macam cara, baik meningkatkan kualitas pelayanan maupun memberikan tempat yang baik dan nyaman bagi para konsumen. Tampilan fisik atau physical evidence di jasa perawatan bisa berupa bentuk bangunan, ruangan perawatan, meja, kursi, tata letak, penampilan karyawan, tempat parkir dan lain sebagainya. Hal ini ditunjukkan salon Noona Beuty Korea di Barabai Kabupaten Hulu Sungai Tengah tengah dengan fluktuasi adanya pelanggan baru yang dari tahun ke tahun mengalami perubahan. Perubahan ini tentunya diharapkan menjadi lebih baik atau peningkatan yang signifikan bagi penambahan pelanggan atau konsumen, jika bukti fisik atau physical evidence yang dimiliki perusahaan dapat memberikan kenyamanan bagi konsumen

Menurut Lupiyoadi (2006) Adapun faktor lain yang menjadi pertimbangan keputusan konsumen memilih salon Noona Beuty Korea di Barabai Kabupaten Hulu Sungai Tengah tengah adalah Citra merek. Pemilihan pada salon dengan citra merek (brand image) yang baik akan lebih diprioritaskan guna memenuhi kebutuhannya, karena pencitraan yang baik suatu salon akan mendapatkan nilai positif di mata konsumen dan juga dapat memberikan gambaran mengenai kualitas salon tersebut. Alma (2007) mengemukakan bahwa terdapat beberapa variabel yang menimbulkan brand image, diantaranya meliputi tenaga medis, teknologi perawatan, biro konsultan, dan produk. Menurut Schiffman dan Kanuk (dalam Pradityas, 2011) menyebutkan faktor-faktor pembentuk citra merek adalah produk yang baik, mendapatkan kepercayaan masyarakat, dapat bermanfaat bagi orang banyak, dapat dipertanggungjawabkan, harga, menarik dan dibutuhkan masyarakat serta berkualitas. 
Selain itu, dalam memilih salon juga memperhatikan bauran pemasaran salon kencantikan yaitu produk, harga, tempat, promosi, orang, proses dan tampilan fisik. (Alma, 2007). Citra merk dapat juga diartikan sebagai sebuah reputasi lembaga yang dimata masyarakat bisa menjadi baik atau buruk tergantung pada merek itu sendiri. Jika merek dapat berguna dan bermanfaat bagi masyarakat luas, maka citra atau tanda yang disematkan pada produk tersebut akan baik juga, tetapi jika produk yang dihasilkan tidak sesuai dengan dengan apa yang ditawarkan, maka label atau tanda yang melekat pada merek tersebut akan menjadi jelek. Hal ini biasanya yang sangat kuat pemasarannya lewat mulut ke mulut atau dalam istilah asing disebut word of mouth (Ali Hasan, 2010).

Berdasarkan faktor-faktor tersebut yang mempengaruhi minat beli pada salon Noona Beuty Korea di Barabai Kabupaten Hulu Sungai Tengah dengan didasarkan pada proses pencarian data tersebut, peneliti tertarik untuk mengkaji lebih jauh ketertarikan konsumen terhadap salon Noona Beuty Korea di Barabai Kabupaten Hulu Sungai Tengah.

\section{TINJAUAN TEORITIS}

\section{Tampilan Fisik}

Tampilan Fisik atau Physical Evidence menurut Kotler (2011: 167) adalah segala bentuk fisik yang dimiliki oleh perusahaan untuk ditunjukkan pada konsumen sebagai penyedia kebutuhan konsumen. Sedangkan menurut pendapat ahli lain, Ratih Nurhayati (2005:64) mengemukakan bahwa bukti fisik (physical evidence) adalah sarana fisik yang merupakan suatu hal yang secara nyata turut mempengaruhi keputusan untuk membeli dan menggunakan barang maupun jasa. Bukti fisik adalah keadaan atau kondisi yang didalamnya juga termasuk suasana tempat tempat belajar, lahan parkir dan sebagainya. Tentunya ini menjadi bukti bahwa dengan adanya bukti atau tampilan fisik tentunya menambah kepercayaan masyarakat dalam menggunakan fasilitas yang dimiliki oleh perusahaan.

Ada tiga cara dalam mengelola bukti fisik yang strategis (Nugroho dan Japarianto, 2013), yaitu : 
a. An attention-creating medium, perusahaan memberikan sesuatu produk atau layanan jasa yang berbeda dengan para pesainya agar lebih menarik konsumen untuk menggunakan jasa atau produknya.

b. As a message-creating medium, artinya perusahaan dapat menggunakan kekuatan lambang atau simbul untuk dapat mengkomunikasikan dengan para konsumennya. Dengan lambing atau symbol atau logo, secara tidak langsung masyarakat akan tahu produk apa yang ditawarkan oleh perusahaan.

c. An effect-creating medium, yaitu kelengkapan yang dipakai oleh karyawan atau pegawai untuk memberikan tanda atau symbol perusahaan tersebut. Hal ini biasanya terdiri dari warna, corak, gambar maupun desain.

Merupakan suatu bukti yang nyata bahwa adanya bukti fisik, logo, warna serta barang lainnya yang disatukan dalam suatu produk akan dapat menentukan konsumen dalam menggunakan jasa atau produk tersebut. Selain itu bangunan fisik sangat mempengaruhi juga dalam kepercayaan konsumen. Bangunan fisik yang baik, serta memadahi akan membuat konsumen merasa yakin dalam membeli atau menggunakan produk. Hal ni disebabkan karena apabila terjadi masalah atau pengaduan jadi lebih gampang dan mudah mengurusnya.

\section{Citra Merek}

Kekuatan merek sangat besar sekali untuk menjaring atau menarik minat konsumen dalam membeli produk serta usaha yang ditawarkan oleh perusahaan. Dengan adanya citra merek yang baik, tentunya akan mendorong masyarakat atau konsumen untuk membeli atau mempergunakan barang dan jasa yang ditawarkan oleh perusahaan tersebut. Perusahaan akan selalu menjaga reputasai dengan baik agar produk yang ditawarkan pada masyarakat mendapat respon positif. Citra merek akan lebih kuat, jika dalam pemasarannya tentunya menggunakan jasa public figure untuk mempromosikan produknya. Salah satu contoh misalnya produsen sepatu 
olah raga Nike, yang didalamnya terdapat olahragawan terkenak Ronaldo sebagai brand ambasadornya.

Pendapat Kotler dan Gary Armstrong (2007) dimana "Brand Image keyakinan yang diberikan pada perusahaan kepada khalayak ramai untuk mempergunakan barang atau jasa yang ditawarkan. Brand image menjadi baik jika perusahaan meyakinkan konsumen dangan promosi dan keynataan yang diperoleh konsumen sesuai. Citra produk dan makna asosiasi brand dikomunikasikan oleh iklan dan media promosi lainnya, termasuk public relation dan event sponsorship.

Iklan mempunyai peranan yang sangat penting bagi perusahaan untuk memperkenalkan produknya kepada masyarakat. Saluran iklan dapat dilakukan dengan berbagai cara, diantaranya dengan melalui media cetak maupun media elektronik. Selain itu, dalam menarik konsumen melalui iklan, perusahaan juga menggunakan tokoh atau public figure sebagai media memperkenalkan produk tersebut agar dikenal lebih cepat dengan orang lain.

\section{Pemasar Dari Mulut ke Mulut}

Word of mouth adalah komunikasi pemasaran yang dipakai secara alamiah tanpa disengaja melalui mulut kemulut untuk menceritakan pengalaman yang dialami oleh pengguna jasa agar ikut memnggunakan produk atau jasa yang sama yang dapat memenuhi keinginan dari konsumen tersebut.

Menurut Hasan (2010), word of mouth adalah pemasaran gratis yang dibantu oleh orang untuk memperkenalkan produk dari suatu perusahaan, karena orang tersebut sudah menggunakannya sehingga akan bercerita pada orang lain tentang apa yang telah dialaminya.

Sedangkan Menurut Sernovitz (2009), word of mouth adalah pembicaraan yang secara alami terjadi antara orang-orang. Word of mouth adalah pembicaraan konsumen asli.

Menurut Kotler (2009) ada dua manfaat utama dalam melakukan Word of mouth (WOM), yaitu :

a. Sumber dari mulut ke mulut meyakinkan 
Cerita dari mulut ke mulut adalah satu-satunya metode promosi yang berasal dari konsumen, oleh konsumen, dan untuk konsumen. Pelanggan yang merasa puas tidak hanya akan membeli kembali, tetapi mereka juga adalah reklame yang berjalan dan berbicara untuk bisnis yang dijalankan.

b. Sumber dari mulut ke mulut memiliki biaya yang rendah

Dengan tetap menjaga hubungan dengan pelanggan yang puas dan menjadikan mereka sebagai penyedia akan membebani bisnis yang dijalankan dengan biaya yang relatif rendah.

Berdasarkan pendapat Sernovitz (2009), Word of mouth terdiri dari dua jenis, yaitu:

a. Organic word of mouth adalah pembicaraan yang bersemi secara alami dari kualitas positif dari perusahaan anda.

b. Amplified word of mouth adalah pembicaraan yang dimulai oleh kampanye yang disengajakan untuk membuat orang-orang berbicara.

Menurut Ivanovic dan Collin (2004), "word of mouth communication adalah saluran informal dari komunikasi seperti teman dan tetangga, rekan kerja dan anggota keluarga."

Menurut Sernovitz (2009), “word of mouth sangat baik untuk keinerja pemasaran, sebab tidak butuh modal untuk memasarkan produk barang atau jasa, dan tidak butuh tenaga marketing, karena konsumen sudah membantu pemasaran perusahaan lewat pengalamannya.."

\section{Keputusan Pembelian}

Pengambilan keputusan konsumen pada dasarnya merupakan proses pemecahan masalah. Kebanyakan melalui proses mental yang hampir sama dalam memutuskan produk merek apa yang dibeli. Walaupun nyata sekali bahwa berbagai konsumen akhirnya memilih untuk membeli barangbarang yang berbeda disebabkan oleh perbedaan karakteristik pribadi (kebutuhan, manfaat, sikap, nilai pengalaman masa lalu dan gaya hidup) dan pengaruh sosial (perbedaan kelas sosial, kelompok rujukan atau kondisi keluarga) (Boyd, 2000). 
Pengambilan keputusan adalah serangkaian aktivitas yang dilakukan seseorang, dalam usaha memecah permasalahan yang sedang dihadapi kemudianmenetapkan berbagai alternatif yang dianggap paling rasional sesuai lingkungan organisasi (Siswanto, 2005).

Keputusan menurut kotler (2002) adalah sebuah hasil akhir seseorang dalam menentukan sikap untuk memilih sesuatu yang diinginkan .

Pengambilan keputusan merupakan suatu kegiatan individu yang secara langsung terlibat dalam mendapatkan dan mempergunakan barang yang ditawarkan. Keputusan juga harus menjawab pertanyaan, tentang apa yang harus dan dilakukan dan apa yang dibicarakan dalam hubunganya dengan perencanaan. Keputusan merupakan tindakan terhadap pelaksanaan yang sangat menyimpang dari rencana semula. Keputusan yang baik pada dasarnya dapat digunakan membuat rencana dengan baik pula (Putri, 2016).

\section{METODE PENELITIAN}

Jenis Penelitian ini merupakan penelitian deskriptif kuantitatif yang bermaksud menjelaskan hubungan kausal antar variabel melalui pengujian hipotesis. Sehingga penelitian ini termasuk dalam jenis eksplanatori yaitu jenis penelitian yang bertujuan mencari potensi-potensi hubungan-hubungan antara satu variabel dengan variabel lainnyaatau bagaimana suatu variabel mempengaruhi variabel lainnya. (Basuki, 2021).

Penelitian ini dilakukan pada salon Noona Beuty Korea di Barabai Kabupaten Hulu Sungai Tengah tengahdengan obyek penelitian konsumen salon Noona Beuty Korea di Barabai Kabupaten Hulu Sungai Tengah. Sampel penelitian ini sebanyak 100 orang dengan teknik pengambilan sampel random sampling. Adapun teknik pengumpulan data dengan kuesioner menggunakan skala pengukuran likert $1-5$. Alat analisis yang dipakai uji instrument penelitian, analisis regresi linier berganda, uji t, uji $F$ dan $\mathrm{Uji}^{2}$

\section{HASIL PENELITIAN}

1. Uji Validitas 
Berdasarkan hasil uji validitas, semua instrumen dinyatakan valid.

2. Uji Reliabilitas

Berikut tabel reliabilitas yang telah direkap:

Tabel 1

Uji Reliabilitas

\begin{tabular}{llll}
\hline Variabel & $\begin{array}{l}\text { Cronbach } \\
\text { Alpha }\end{array}$ & $\begin{array}{l}\text { Batas } \\
\text { Minimal }\end{array}$ & Keterangan \\
\hline Tampilan Fisik & 0,794 & 0,6 & Reliabel \\
Citra Merek & 0,758 & 0,6 & Reliabel \\
Pemasar dari mulut ke mulut & 0,773 & 0,6 & Reliabel \\
Keputusan Pembelian & 0,746 & 0,6 & Reliabel \\
\hline
\end{tabular}

Sumber: Data diolah 2021

Karena nilai Cronbach Alpha (á), apabila Cronbach Alpha $>0,60$ maka butir pernyataan instrumen dinyatakan reliabel.

3. Asumsi Klasik

Berdasarkan hasil uji asumsi klasik, semua variabel memenuhi syarat.

Analisis data

a. Analisis Regresi Linier Berganda

Hasil uji persamaan regresi linear berganda yang diperoleh persamaan regresinya $\mathrm{Y}=-11,514+0,431 \mathrm{X} 1+0,830 \mathrm{X} 2+1,235 \mathrm{X} 3$.

Berikut tabel analisis regresi linier berganda dan uji $\mathrm{t}$

Tabel 4

Tabel Regresion

\begin{tabular}{|c|c|c|c|c|c|c|c|}
\hline & \multirow[b]{2}{*}{ Model } & \multicolumn{2}{|c|}{$\begin{array}{l}\text { Unstandardized } \\
\text { Coefficients }\end{array}$} & \multicolumn{2}{|c|}{$\begin{array}{c}\text { Standardized } \\
\text { Coefficients }\end{array}$} & \multirow[b]{2}{*}{$\mathrm{t}$} & \multirow[b]{2}{*}{ Sig. } \\
\hline & & B & $\begin{array}{l}\text { Std. } \\
\text { Error }\end{array}$ & Beta & & & \\
\hline \multirow[t]{4}{*}{1} & (Constant) & -11.514 & 6.335 & & & -1.817 & .072 \\
\hline & Tampilan Fisik & .431 & .216 & & .189 & 1.999 & .048 \\
\hline & Citra Merek & .830 & 220 & & .323 & 3.773 & .000 \\
\hline & Mulut Ke Mulut & 1.235 & 415 & & .284 & 2.979 & .004 \\
\hline
\end{tabular}

Sumber : Olah Data SPSS 2021

b. Uji-t

Pengaruh Tampilan Fisik Terhadap Keputusan Pembelian di Salon Noona Beauty Korea Barabai Kabupaten Hulu Sungai Tengah diperoleh hasil t hitung $=1,999>\mathrm{t}$ tabel $=1,984$ dengan sig.0,048 $<0,05$ maka dapat 
disimpulkan Tampilan Fisik (X1) berpengaruh secara signifikan terhadap Keputusan Pembelian.

Pengaruh Citra Merek (X2) terhadap Keputusan Pembelian (Y) ) di Salon Noona Beauty Korea Barabai Kabupaten Hulu Sungai Tengah diperoleh hasil $\mathrm{t}$ hitung $=3,773>\mathrm{t}$ tabel $=1,984$ dengan signifikasinya $0,000<0,05$ maka terdapat pengaruh antara Citra Merek (X2) terhadap Keputusan Pembelian (Y) ) di Salon Noona Beauty Korea Barabai Kabupaten Hulu Sungai Tengah.

Pengaruh Pemasar dari mulut ke mulut (X3) terhadap Keputusan Pembelian di Salon Noona Beauty Korea Barabai Kabupaten Hulu Sungai Tengah diperoleh hasil $\mathrm{t}$ hitung $=2,979>\mathrm{t}$ tabel $=1,984$ dengan tingkat signifikan $0,004<0,05$, maka Ho di tolak, berarti terdapat pengaruh antara Pemasar dari mulut ke mulut (X3) terhadap Keputusan Pembelian (Y) di Salon Noona Beauty Korea BarabaiKa bupaten Hulu Sungai Tengah.

c. Uji F

Tabel 5

Uji Anova

\begin{tabular}{|c|c|c|c|c|c|c|}
\hline & Model & Sum of Squares & $\mathrm{df}$ & $\begin{array}{c}\text { Mean } \\
\text { Square }\end{array}$ & $\mathrm{F}$ & Sig. \\
\hline \multirow[t]{3}{*}{1} & Regression & 912.904 & 3 & 304.301 & $\begin{array}{r}15.88 \\
3\end{array}$ & $.000^{\mathrm{a}}$ \\
\hline & Residual & 1839.286 & 96 & 19.159 & & \\
\hline & Total & 2752.190 & 99 & & & \\
\hline
\end{tabular}

Sumber: data yang diolah 2021

Secara bersama-sama antara variabel independent yang berupa Tampilan Fisik (X1), Citra Merek (X2), Pemasar dari mulut ke mulut (X3) terhadap Keputusan Pembelian (Y) di Salon Noona Beauty Korea Barabai Kabupaten Hulu Sungai Tengah diperoleh hasil F hitung $=15,883>\mathrm{F}$ tabel $=2,70$, maka Ho ditolak yang berarti terdapat pengaruh secara bersama-sama antara variabel independent yang berupa Tampilan Fisik (X1), Citra Merek (X2), Pemasar dari mulut ke mulut (X3) terhadap Keputusan Pembelian (Y) di Salon Noona Beauty Korea Barabai Kabupaten Hulu Sungai Tengah. Hipotesis yang berbunyi Tampilan Fisik (X1), Citra Merek (X2), Pemasar dari mulut ke mulut 
(X3) berpengaruh secara bersama-sama terhadap Keputusan Pembelian (Y) di Salon Noona Beauty Korea Barabai Kabupaten Hulu Sungai Tengah terbukti kebenarannya. Analisis Koefisien Determinasi $\left(\mathrm{R}^{2}\right)$ diperoleh untuk $\mathrm{R}^{2}$ sebesar 0,311 atau $31,1 \%$, artinya bahwa secara bersama-sama terdapat pengaruh antara variabel independen yaitu Tampilan Fisik (X1), Citra Merek (X2), Pemasar dari mulut ke mulut (X3) terhadap Keputusan Pembelian (Y) di Salon Noona Beauty Korea Barabai Kabupaten Hulu Sungai Tengah sebesar $31,1 \%$, sedangkan yang $68,9 \%$ dipengaruhi oleh faktor lain, yang tidak diteliti seperti lokasi, sarana dan prasarana, kualitas produk, harga, motivasi dan lain sebagainya.

\section{E. PEMBAHASAN}

1. Pengaruh Tampilan Fisik (X1) Terhadap Keputusan Pembelian di Salon Noona Beauty Korea Barabai Kabupaten Hulu Sungai Tengah

Uji t yang berkaitan dengan pengaruh Tampilan Fisik (X1) terhadap Keputusan Pembelian (Y) di Salon Noona Beauty Korea Barabai Kabupaten Hulu Sungai Tengah diperoleh hasil $\mathrm{t}$ hitung $=1,999>\mathrm{t}$ tabel $=$ 1,984 dengan sig.0,048 < 0,05 maka dapat disimpulkan Tampilan Fisik (X1) berpengaruh secara signifikan terhadap Keputusan Pembelian (Y) di Salon. Hal ini diperkuat penelitian Hurriyati (2005:64), yang menyatakan bahwa bukti fisik dikatakan baik jika suasana dari perusahaan yang menunjang seperti visual, aroma, suara, tata ruang, dan lain-lain sesuai dengan keinginan konsumen.

Berdasarkan uraian di atas, hipotesis yang diajukan dalam penelitian ini adalah Tampilan Fisik berpengaruh positif dan signifikan terhadap Keputusan Pembelian di Salon Noona Beauty Korea Barabai Kabupaten Hulu Sungai Tengah terbukti kebenarannya.

2. Hubungan Citra Merek (X2) terhadap Keputusan Pembelian (Y) ) di Salon Noona Beauty Korea Barabai Kabupaten Hulu Sungai Tengah

Uji t yang berkaitan dengan pengaruh Citra Merek (X2) terhadap Keputusan Pembelian (Y) ) di Salon Noona Beauty Korea Barabai 
Kabupaten Hulu Sungai Tengah diperoleh hasil $\mathrm{t}$ hitung $=3,773>\mathrm{t}$ tabel $=$ 1,984 dengan signifikasinya $0,000<0,05$ maka terdapat pengaruh antara Citra Merek (X2) terhadap Keputusan Pembelian (Y) ) di Salon Noona Beauty Korea Barabai Kabupaten Hulu Sungai Tengah. Hal ini menjawab hipotesis yang berbunyi Citra Merek (X2) berpengaruh terhadap Keputusan Pembelian (Y) ) di Salon Noona Beauty Korea Barabai Kabupaten Hulu Sungai Tengah terbukti kebenarannya.

Image yang diyakini oleh konsumen dari sebuah merek sangatlah bervariasi dari persepsi masing-masing individu. Apabila image yang tertanam dalam suatu produk baik, maka konsumen akan membeli produk itu untuk dikonsumsi. Namun sebaliknya, jika image yang tertanam benak konsumen mengenai merek tersebut negatif, maka harapan setelah pembelian konsumen akan merasa tidak puas. Image yang positif akan menjadi kekuatan bagi brand yang digunakan produk tersebut. Seperti dalam penelitian Anwar, Gulzar, Fahid, \& Akram, (2011) yang menemukan bahwa brand image suatu produk menentukan tingkat pembelian yang dilakukan konsumen. Semakin baik brand image suatu produk, maka semakin besar dampak pada keputusan konsumen dalam membeli produk tersebut, sehingga dapat terjadi dampak positif seperti pembelian ulang terus-menerus dan menimbulkan kepercayaan pada produk tersebut. Akan tetapi, hasil penelitian Bloemer, deRuyter \& Peeters (1998) justru mengungkapkan brand image tidak memiliki hubungan yang signifikan pada keputusan pembelian konsumen. Karena dianggap brand image tidak mengambil peran yang mampu mempengaruhi konsumen dalam membeli. Hal itu disebabkan adanya variabel lain yang memiliki peran lebih penting dalam mempengaruhi keputusan pembelian konsumen.

3. Hubungan Pemasar dari mulut ke mulut (X3) terhadap Keputusan Pembelian di Salon Noona Beauty Korea Barabai Kabupaten Hulu Sungai Tengah

Uji t yang berkaitan dengan Pemasar dari mulut ke mulut (X3) terhadap Keputusan Pembelian (Y) di Salon Noona Beauty Korea Barabai Kabupaten Hulu Sungai Tengah diperoleh hasil $\mathrm{t}$ hitung $=2,979>\mathrm{t}$ tabel $=$ 1,984 dengan tingkat signifikan $0,004<0,05$, maka Ho di tolak, berarti 
terdapat pengaruh antara Pemasar dari mulut ke mulut (X3) terhadap Keputusan Pembelian (Y) di Salon Noona Beauty Korea Barabai Kabupaten Hulu Sungai Tengah. Jadi hipotesis yang berbunyi Pemasar dari mulut ke mulut (X3) berpengaruh terhadap Keputusan Pembelian (Y) di Salon Noona Beauty Korea Barabai Kabupaten Hulu Sungai Tengah terbukti kebenarannya.

Pemasar dari mulut ke mulut adalah komunikasi dari orang ke orang antara sumber pesan dan penerima pesan dimana penerima pesan menerima pesan dengan cara tidak komersil mengenai suatu produk, pelayanan, atau merek. Pemasar dari mulut ke mulut menjadi referensi yang membentuk harapan pelanggan. Menurut Hasan (2010), word of mouth merupakan pujian, rekomendasi dan komentar pelanggan sekitar pengalaman mereka atas layanan jasa dan produk yang betul - betul mempengaruhi keputusan pelanggan atau perilaku pembelian mereka. Pemasar dari mulut ke mulut dapat membentuk kepercayaan para pelanggan. Komunikasi Pemasar dari mulut ke mulut atau Pemasar dari mulut ke mulut adalah tindakan konsumen memberikan informasi kepada konsumen lain dari seseorang kepada orang lain (antar pribadi) non-komersial baik merek, produk maupun jasa. Komunikasi ini sangat efektif untuk menentukan dan mengajak pelanggan baru untuk ikut mendaftar di perguruan tinggi seperti mengikuti jejak langkah yang dibicarakan. Kemudian selain teori dan pengolahan data hasil penelitian ini juga sejalan dengan penellitian yang penah dilakukan oleh Eka Hafillah (2015) bahwa terdapat pengaruh Word Of Mouth (WOM) Terhadap Keputusan Pelanggan Memilih Strata S-1 Di Universitas Islam Negeri Maulana Malik Ibrahim Malang.

4. Secara bersama-sama antara variabel independent yang berupa Tampilan Fisik (X1), Citra Merek (X2), Pemasar dari mulut ke mulut (X3) terhadap Keputusan Pembelian (Y) di Salon Noona Beauty Korea Barabai Kabupaten Hulu Sungai Tengah diperoleh hasil F hitung $=15,883>$ F tabel $=$ 2,70, maka Ho ditolak yang berarti terdapat pengaruh secara bersama-sama antara variabel independent yang berupa Tampilan Fisik (X1), Citra Merek 
(X2), Pemasar dari mulut ke mulut (X3) terhadap Keputusan Pembelian (Y) di Salon Noona Beauty Korea Barabai Kabupaten Hulu Sungai Tengah. Hipotesis yang berbunyi Tampilan Fisik (X1), Citra Merek (X2), Pemasar dari mulut ke mulut (X3) berpengaruh secara bersama-sama terhadap Keputusan Pembelian (Y) di Salon Noona Beauty Korea Barabai Kabupaten Hulu Sungai Tengah terbukti kebenarannya.

5. Analisis Koefisien Determinasi $\left(\mathrm{R}^{2}\right)$

Dengan mengunakan program SPSS, maka dapat diperoleh untuk $\mathrm{R}^{2}$ sebesar 0,311 atau $31,1 \%$, artinya bahwa secara bersama-sama terdapat pengaruh antara variabel independen yaitu Tampilan Fisik (X1), Citra Merek (X2), Pemasar dari mulut ke mulut (X3) terhadap Keputusan Pembelian (Y) di Salon Noona Beauty Korea Barabai Kabupaten Hulu Sungai Tengah sebesar $31,1 \%$, sedangkan yang $68,9 \%$ dipengaruhi oleh faktor lain, yang tidak diteliti seperti lokasi, sarana dan prasarana, kualitas produk, harga, motivasi dan lain sebagainya.

\section{KESIMPULAN}

a. Terdapat pengaruh Tampilan Fisik (X1) Terhadap Keputusan Pembelian di Salon Noona Beauty Korea Barabai Kabupaten Hulu Sungai Tengah

b. Terdapat pengaruh Citra Merek (X2) terhadap Keputusan Pembelian (Y) di Salon Noona Beauty Korea Barabai Kabupaten Hulu Sungai Tengah.

c. Terdapat pengaruh Pemasar dari mulut ke mulut (X3) terhadap Keputusan Pembelian di Salon Noona Beauty Korea Barabai Kabupaten Hulu Sungai Tengah

d. Terdapat pengaruh secara bersama-sama antara variabel independent yang berupa Tampilan Fisik (X1), Citra Merek (X2), Pemasar dari mulut ke mulut (X3) terhadap Keputusan Pembelian (Y) di Salon Noona Beauty Korea Barabai Kabupaten Hulu Sungai Tengah. 


\section{Saran}

a. Untuk tampilan fisik perlu pembenahan lagi, khususnya diruang perawatan diharapkan lebih privacy, sehingga konsumen lebih nyaman dan tenang

b. Ditingkatkan lagi ctra mereknya, dengan meningkatkan legalitas usaha agar lebih dipercaya masyarakat luas

c. Selain pemasar dari mulut ke mulut, perlu juga pemasar melalui media sosial dan media cetak, sehingga akan lebih dikenal di masyarakat secara luas

d. Bagi peneliti selanjutnya diperlukan penelitian lebih lanjut mengenai pengambilan keputusan pembelian pada konsumen karena masih ada beberapa variabel lain selain tampilan fisik, brand image dan pemasar dari mulut ke mulut, seperti produk, harga dan lain sebagainya.

\section{DAFTAR PUSTAKA}

Arikunto Suharsimi, 2006. Prosedur Penelitian : Suatu Pendekatan Praktik. Jakarta : Rineka Cipta.

Aris Ananda. 2012. Manajemen Ekuitas Merek: Memanfaatkan Nilai Dari Suatu Merek. Jakarta: Spektrum Mitra Utama

Assauri. 2014. Manajemen Pemasaran. Jakarta: Raja Grafindo Persada

Basuki, 2021, Pengantar Metode Penelitian Kuantitatif, Penerbit Media Sains Indonesia, Bandung.

Boyd.2000. Manajemen Pemasaran Suatu Pendekatan Strategis dengan Orientasi Global Edisi 2 Jilid 1. Jakarta: Erlangga.

Buchari Alma. 2007. Manajamen Pemasaran dan Pemasaran Jasa. Bandung: Alfabeta

Buchari Alma. 2011. Manajemen Pemasaran Dan Pemasaran Jasa. Bandung: Penerbit Alfabeta

Chin. 1998. The Partial Least Squares Aproach to Structural Equation Modeling. Modern Methods for Business Research

Dharmmaesta. 2014. Manajemen Pemasaran. Yogyakarta: BPFE

Ghozali, I.2005. Aplikasi Analisa Multivariate dengan SPSS. Semarang Badan Penerbit UNDIP Semarang.

Gitosudarmo. 2014. Manajemen Operasi. Yogyakarta. BPFEYogyakarta

Hamalik. 2013. Proses Belajar Mengajar Jakarta : PT.Bumi Aksara

Hasan. 2010. Marketing. Yogyakarta: Media Presindo.

Hurriyati. 2009. Bauran Pemasaran dan Loyalitas Konsumen. Bandung: ALFABETHA. 
Ivanovic dan Collin. 2004. Dictionary Of Marketing. Third. Edition. Bloomsbury Publishing Plc. United States Of America

Kotler \& Keller. 2009. Manajemen Pemasaran. Jakarta. Erlangga

Kotler Philip dan Gary Amstrong. 2012. Principle of Marketing, Global Editon, 14 Editon, Pearson Education.

Kotler philip dan Kevin Lane keller. 2009. Manajemen Pemasaran, Edisi 12. Jakarta. PT.Indeks

Laksana. 2008. Manajemen Pemasaran. Yogyakarta: Penerbit Graha Ilmu

Lupiyoadi. 2006. Manajemen Pemasaran jasa Edisi kedua. Jakarta: Penerbit Salemba Empat

Malcolm, dkk. 200). Absence from school: A study of its causes and effects in seven LEAs. Notingham: Department for education and skills

Nasir. 2005. Metode Penelitian. Bogor: Ghalia Indonesia

Nunally dalam Sugiyono. 2006. Psychometric Theory 3rd edition. New York: McGraw-Hill

Pangestu Subagyo, 2002. Statistik Induktif, Yogyakarta: BPFE

Peter dan Olson. 2014. Perilaku Konsumen Dan Strategi Pemasaran. Edisi Sembilan. Jakarta: Salemba empat.jakarta.

Rahman. 2010. Panduan Pelaksanaan Adminitrasi Pajak:Untuk Karyawan, Pelaku Bisnis Dan Perusahaan. Bandung: Nuansa.

Ratih Nurhayati. 2005. Bauran Pemasaran dan Loyalitas Konsumen, Bandung Alfabeta

Schiffman dan Kanuk (dalam Pradityas, 2011). Customer Behavior, USA: Prentice Hall In

Schoell. 2016. Manajemen Pemasaran dan Pemasaran Jasa Edisi Revisi', Bandung : Penerbit ALFABETA

Sernovitz, Andi. 2009. Word of mouth Marketing: How Smart Companies Get People Talking. New York: Kaplan

Setiadi. 2003. Perilaku Konsumen: Konsep dan Implikasi untuk Strategi dan Penelitian Pemasaran. Jakarta: Prenada Media.

Siswanto. 2005. Manajemen Tenaga Kerja Indonesia Pendekatan. Administrarif dan Operasional. Jakarta: Bumi Aksara

Sugiyono. 2005. Memahami Penelitian Kualitatif. Bandung: CV. Alfabeta.

Sugiyono. 2010. Statistika Untuk Penelitian. Bandung : Alfabeta.

Sugiono. 2009. Metode Penelitian Kualitatif, Kuantitatif . Bandung. Alfabeta

Sugiyono. 2017. Metode Penelitian Kuantitatif, Kualitatif, dan R\&D. Bandung: Alfabeta

Supriadi. 2010. Strategi Belajar Mengajar. Yogyakarta: Cakrawala Ilmu

Susanto. 2001. Manajemen Pemasaran di Indonesia. Jakarta: Salemba Empat

Sutisna. 2012. Perilaku Konsumen dan Komunikasi Pemasaran, Edisis kedua,. Bandung: Remaja Rosdakarya

Swastha. 1999. Manajemen Pemasaran Modern, Edisi 2,. Yogyakarta : Liberty.

Syamsi, Ibnu. 2007. Pengambilan Keputusan dan Sistem Informasi. Jakarta : Bumi Aksara

Tjiptono. 2009. Strategi Pemasaran. Yogyakarta. Andi Offset 
Volume 7 Nomor 2, Oktober 2021

Yazit. 2005. Pemasaran Jasa Konsep dan Implementasi, Edisi Kedua, Yogyakarta: Ekonesia.

Widyanto, Rahmi, 2021. Perilaku Organisasi, Teori dan Konsep, Media Sains Indonesia, Bandung

William Shoell (dalam Abdurrahman 2015). Manajemen Pemasaran dan Pemasaran Jasa Edisi. Revisi', Bandung : Penerbit ALFABETA 